Final Draft - published version is available from

http://doi.org/10.1061/(ASCE)CO.1943-7862.0000642

Authors:

Heap Yih Chong, Rosli Mohamad Zin and Siong Choy Chong

Further reference acknowledgements:

Al-Sabah, S. S. J. A., Fereig, S. M., and Hoare, D. J. (2003). "A database

management system to document and analyse construction claims." Adv. Eng. Softw., 34(8), 477-491.

Hsu, Y. L., Lee, C. H., and Kreng, V. B. (2010). "The application of Fuzzy Delphi Method and Fuzzy AHP in lubricant regenerative technology selection." Expert Syst. Appl., 37(1), 419-425. 


\section{Employing Data Warehouse for Contract Administration: e-Dispute Resolution Prototype}

33 Abstract: Although data warehouse is very practical for decision making, its application in contract 34 administration is rather limited due to the complicated legal issues and the voluminous data involved. This 35 research attempts to bridge this gap in two ways. First, conceptual models of data warehouse are developed 36 to explain the contents and overall features of the system which were verified by twelve experts in 37 Malaysia. Second, a template, e-Dispute Resolution (e-DR), is prototyped using Microsoft Access based on

38 the guidelines of contractual variations agreed by the experts. Subsequently, the prototype is evaluated by 39 sixteen professional quantity surveyors from an established consulting firm. The prototype was organized

40 based on a systematic breakdown of issues and incorporated a Boolean keyword search feature. The results

41 show that the concept of data warehouse is applicable to contract administration and is well received by

42 practitioners. Overall, this article renders significant theoretical and practical contributions where the 43 resulting e-DR does not only lead toward a more informed decision making, but is also able to mitigate or 44 prevent contractual disputes in the construction industry where such a phenomenon seems to be inevitable.

46 Keywords: Database application; Contract administration; Data warehouse; e-Dispute Resolution;

47 Contractual variations; Construction industry.

\section{INTRODUCTION}

50 The construction industry is known to be fragmented and adversarial in nature (Cheung and Yiu 51 2007; Ajam et al. 2010). Every construction project is bound to have contractual conflicts or 52 disputes due to high risk and degree of complexity of the project (Kim et al. 2008). Even though

53 contract administration regulates contractual obligations and expectations between the contracting 54 parties, contractual variations have been found to be among the most common cause of disputes 55 in the industry (Charles and Bruce 1990; Semple et al. 1994; Zaneldin 2006; Perkins 2009; Serag 56 et al. 2010). These variations or changes are unfavorable in construction projects in the context of 57 contractual commitments and effective implementation of the project (Moselhi et al. 2005; 
58 Anastasopoulos et al. 2010). This is particularly true with regards to issues concerning

59 interpretation and understanding of construction contracts due to the illegibility of contract

60 clauses and the use of legalese or complicated terms (Thomas et al. 1994; Broome and Hayes

61 1997; Shumway et al. 2004; Rameezdeen and Rajapakse 2007).

62 The problem is further compounded by the increasingly complicated legal issues,

63 voluminous data involved, and contractual requirements of a construction project. Further,

64 judgments from litigation cases create numerous legal views or positions into the practice of

65 contract administration. The lack of understanding of the contract provisions and jurisdiction of

66 legal cases is a common problem in the construction industry, as most of the users do not possess

67 a legal background (Chong and Zin 2010). All these issues lead to contractual conflicts and

68 disputes. Although previous studies have identified information technology (IT) as one of the

69 possible measures of mitigating conflicts and disputes (Cheung et al. 2004; Nitithamyong and

70 Skibniewski 2004; Chen 2008; Chong et al. 2011), the application of IT in contract administration

71 in the construction industry is rather limited. This offers a fertile ground for research.

72 Data warehousing is a relatively new concept in the development of database and

73 information systems domains (Hwang and Xu 2008; Inmon and Valente 2010). In fact, it is a

74 collection of methods used to support users in conducting data analysis for the purpose of

75 decision making and improving information resources (Inmon 2002; Rahman 2007). In the

76 context of this paper, construction contracts are considered textual data in data warehouse.

77 However, these data are yet to be effectively introduced in business decision making. This is

78 simply because the basic database technology is designed for repetitive events and structured data

79 such as transactions, whereas textual data are not repetitive and are unstructured (Russell et al.

80 2009). As pointed out by Inmon and Valente (2010), the greatest concern is the visceral mismatch

81 between the structure of a database and the lack of textual structure. Nevertheless, the application

82 of data warehousing should be able to perform data analysis, reporting, and query tools to help 
83 the users swift through tonnes of data and extract valuable information from them (Gupta and

84 Mumick 2005).

85 Due to this challenge, the development of data warehouse for contract administration

86 (DWCA), particularly its contents and application features, needs to be well thought of. The

87 objectives of the study are (a) to develop a conceptual process flow model for incorporating the

88 data warehouse technology into the construction contract administration, and (b) to develop the e-

89 Dispute Resolution (e-DR) prototype based on the resulting DWCA model depicting contractual

90 variations.

91 Consequently, the outcome of this study will allow improved contract administration,

92 which will possibly be adjusted and adopted in other countries, especially the Commonwealth

93 countries which share similar common law system. Notwithstanding the limitations highlighted at

94 the end of the paper, this research makes significant theoretical and practical contributions where

95 it sets directions for future research and the possibility of replicating the same study in different

96 countries with similar or diverse legal systems.

97 This paper is structured as follows. It first reviews the literature concerning data

98 warehouse, followed by a description of the research approach used in this study. Next, the

99 resulting DWCA model is explained. Subsequently the e-DR prototype development is

100 illuminated. The following section presents the evaluation results of the prototype before its

101 implications are discussed. The paper is then concluded.

102

103 DATA WAREHOUSE FOR CONTRACT ADMINISTRATION

\section{Previous approaches}

106 Previous studies concerning IT application in contract administration were analyzed and

107 compared. Table 1 presents the details of nine related studies that were conducted between 1988

108 and 2011. Generally, it can be concluded that previous studies have dealt with both general 
109 construction disputes and specific issues within contract administration. In addition, it can be

110 observed that IT concepts and applications play a role in enhancing the usability and flexibility of

111 a decision support system. However, the studies suffered from methodology weaknesses in one

112 way or another such as the absence of verification by a panel of experts, contract forms, and

113 historical/court cases. Such an overview renders a useful insight in terms of bridging the gaps

114 available in the literature as well as practice. It is apparent that the development of DWCA from

115 the decision-making perspective has not been thoroughly investigated, although data warehouse

116 has been identified as a very practical tool in data application for organizations (Hwang and Xu

117 2008). The developed DWCA model therefore highlights a significant area of improvement for

118 traditional contract administration (Chong et al. 2011). It motivates the development of e-DR

119 prototype in this research.

120

121 Data warehouse: New breed of decision support systems in contract administration

122 Data warehouse is a read-only database created by combining data from multiple databases for 123 purposes of analysis and decision making (Theodoratos and Sellis 1999). The contents of a data

124 warehouse may be a reproduction of a part of some source data or the results of preprocessed 125 queries or both (Chau et al. 2002). This approach of data storage provides a useful guide in 126 making decisions. As a matter of fact, data warehouse has been recognized as a type of decision 127 support systems. In this context, it is an analytical database that efficiently collects, organizes, 128 and stores all relevant data in support of management decisions (Chau et al. 2002; Rujirayanyong 129 and Shi 2006). It ensures that the users could access or retrieve the data for references and 130 decision making at the appropriate time during the contract administration period. The 131 characteristics of data warehouse technology thus motivate the need for a new breed of decision 132 support systems in contract administration.

133 
137 The research and development works consist of two main activities. The first activity comprises

138 of the DWCA model development, and the second involves the development of e-DR prototype

139 based on the most problematic issues of contractual variations. The prototype is named as e-DR

140 following the terms (e-Dispute Resolution) for purposes of simplicity and easy to remember.

141 Coincidently the acronym 'DR' appears in a way which denotes a medical doctor, which is

142 aligned to the purpose of this study. These two main activities were simultaneously carried out

143 with input sought from twelve experts using the mini Delphi approach to validate the model and

144 agree on the guidelines on contractual variations for the contents of e-DR. The details of the

145 experts are shown in Table 2. They were chosen based on profession and a wide range of

146 expertise related to construction contract administration. All the experts have had more than 20

147 years of working experience. They are either directors or partners in their respective companies

148 and hold significant roles in their respective professional bodies.

149 The Data Flow Diagram (DFD) method was selected for DWCA model development as

150 this method focuses on the object perspective (Luo and Tung 1999). Specifically, two conceptual

151 models of DWCA were developed to systematically describe the process flow involved in the

152 development of e-DR prototype. These models were developed by referring to the requirements

153 of data warehousing and literature related to construction contract administration. Subsequently,

154 these models were verified and supported by the experts.

155 Meanwhile, the guidelines for contractual variations need to be assessed and commented

156 by the experts for accuracy and completeness of its use for the local industry as the guidelines

157 were derived based on a review of contract provisions from a local contract form, Pertubuhan

158 Arkitek Malaysia (PAM) or Malaysian Institute of Architects 2006, and court cases. For this, two

159 rounds of mini Delphi exercises were conducted and completed after obtaining consensus from

160 the experts. The experts were asked for their degree of agreement using 11-point Likert scale for 
161 the guidelines. This scale was chosen as it could detail out the levels of agreement. The score and

162 definition for the agreements are modified from the related Delphi studies (Liang et al. 2006; Hsu

163 et al. 2010), that is, $0=$ absolutely disagree; $1=$ strongly disagree; $2=$ highly disagree; $3=$ quite

164 disagree; $4=$ slightly disagree; $5=$ neutral; $6=$ slightly agree; $7=$ quite agree; $8=$ highly agree; $9=$

165 strongly agree; and 10= absolutely agree.

166 Subsequently, the score changed from the points 0-10 to 1-11 to facilitate the analysis of

167 geometric mean. The conversion is important to avoid calculation error that might have occurred

168 when calculating zero score. The formula of geometric mean is the positive $n$th root of the twelve

169 experts of a set of $n$ numbers (scores). This analysis is aimed to obtain an easy, comprehendible

170 definite value based on the principle of Centroid method for the defuzzification and normalization

171 process (Hsu et al. 2010). Then, a pre-determined threshold value was applied as selection

172 criteria for the guidelines. The value was modified and classified into three categories (Kuo and

173 Chen, 2008; Chong and Rosli 2010), such as:

$174 \quad$ - $\quad$ Disagree' $=1 \leq$ geometric mean $<4.75$

$175 \quad$ - 'Undecided/Neutral' $=4.75 \leq$ geometric mean $<7.25$

$176 \quad$ • 'Agree' $=7.25 \leq$ geometric mean $\leq 11.00$

177 The guidelines were found to score more than the threshold value (7.25) and as such, they

178 would serve as the contents of e-DR. The details of the contents (Part A) are shown in Appendix

179 A. The rest of the parts (Part B, C, and D) serve as a reference to readers who wish to know the 180 contractual variations in brief.

181

\section{DWCA MODEL}

183

184 A model is a valuable tool to communicate and manage a process requirement or information

185 between entities (Chen et al. 2004; Chen et al. 2010). In this study, two conceptual models of 
186 DWCA using the DFD method were developed. Generally, the models describe the process flow 187 of the e-DR prototype development.

188 The first model (Level-0 DFD) (Figure 1) explains the sequence and processes involved 189 in content development. It demonstrates how a clarified, organized, and reliable source of 190 references regarding the contractual obligations and expectations required for contract 191 administration are produced so as to help users produce better and more informed decision 192 making.

193 As Figure 1 illustrates, the potential disputes or contractual issues form the basis of the

194 Level-0 DFD model. The issues related to the disputes can be categorized into three main stages:

195 (1) pre-contract stages; (2) construction or commencement of work stage; and (3) work

196 completion stage, as shown in Table 3. The issues listed in the work stages are identified from the 197 literature (Chong et al. 2011).

198 Besides, leading court cases, contract provisions, and literatures are important inputs in 199 the DWCA in addressing contractual issues. It is imperative to first consider common law 200 principles and legal positions related to the issues by referring to the court cases in order to 201 enhance the information on contract provisions. Second, the contract clauses and sub-clauses 202 related to the standard contract form are referred to in this study. A reference will be made to the 203 main clause and its sub-clauses of the contract relevant to the contractual issues in addition to 204 other related clauses. All the related clauses will be combined and cross-referenced in order to 205 gain a wider view of the expressed contractual obligations and expectations. In addition, literature 206 sources also contribute in terms of organizing and recognizing the characteristics of the 207 contractual issues from different perspectives. Another consideration is the use of plain English 208 guidelines to enhance contract clarity and to make them more accessible to non-lawyers.

209 Figure 2 shows the second conceptual model (Level-1 DFD) and its features as required 210 by the DWCA. It is designed in such a way that it eases the users in searching for information and 211 providing feedback. Eventually, the resulting e-DR aims at rendering self-examination and a 
212 proactive approach in contract administration whereby the clarified references and/or guidelines 213 are referred to and retrieved by the users.

214 The Level-1 DFD model consists of three main features such as keyword searching by 215 using Boolean exact keyword search principle (Mitra and Chaudhuri 2000), dispute sub216 categories (breakdown of issues), and a forum for comments or discussion. Accordingly, the 217 contractual issues in the three work stages are kept in the database and classified according to the

218 project particulars. The issues can be retrieved by using keyword searching or by selecting the 219 concerned issue from the list of breakdown of issues. The project database is referred to in order 220 to provide a list of choices based on the project features, that is, types of the project (building, 221 road, etc.), contract-payment methods (lump sum contracts, cost reimbursement, etc.), 222 procurement methods (traditional, design and build, etc.), and standard forms of contract [local 223 such as the Public Works Department (PWD) 203A (Revised 10/83) form or international 224 contract forms such as Joints Contract Tribunal, New Engineering Contract, etc.]. The specified 225 particulars of the project will then be sorted out.

226 Subsequently, the targeted contractual issue will be further examined based on the 227 characteristics of the issue in order to investigate and seek the root cause of the main issue. In this 228 process, relevant references or guidelines stored in the database are selected. The database 229 performs two functions. It provides the consensus data by the experts based on the issue's root 230 causes. The next function is to keep all the comments or discussions made by the construction 231 practitioners regarding the particular issue or its sub-topics. It will serve as a forum of discussion 232 for the practitioners in exchanging and sharing information.

233 The models were validated by twelve experts through the mini Delphi process. The 234 experts commended on the extent of comprehensiveness of the models developed and their 235 associated contents. Their involvement and the resulting output generated have greatly enhanced 236 the validity of the models which facilitated the development of the e-DR prototype. 
A prototype, namely e-DR was developed as a result of the developed DWCA models.

241 The e-DR prototype is developed by using Microsoft Access 2007 Developer Extensions and

242 Runtime due to its user-friendly functions and wide availability. The software was used to create

243 a template to be evaluated by the practitioners. However, the prototype focuses only on one of the

244 contractual issues identified in the construction or commencement of work stage, that is,

245 contractual variations (Table 3). Nevertheless, all the relevant tables of the database such as

246 project particulars, issues related to disputes in the three stages [pre-contract stage (pre-issues),

247 construction or commencement of work stage (con-issues), and work completion stage (post-

248 issues)] were developed. The tables and their relationships are illustrated in Figure 3. The One-to-

249 One and One-to-Many relationships were set for the tables to ensure functionality of the data 250 warehouse.

251 In this prototype, the dimension tables are main variations (MainVariations), sub

252 variations (SubVariations), Content, and Forum, whereas the others are fact tables. In total, there 253 are eight tables in DWCA. Project particulars describe the classification on the type of project, 254 contract system, procurement method, and standard form used.

255 The main variations list the four main aspects of contractual variations such as issuance 256 of variations, validity of variations, valuation rules of variations and additional expenses, and 257 subsequent circumstances caused by variations. The sub-variations list the sub-issues from the 258 four main aspects of contractual variations such as authorized persons and power, period of 259 issuance, provisional sums, written instruction, definition/principle of variation, addition, 260 omission, substitution, alteration of the kind or standard of materials or goods, removal of 261 executed works, materials and goods, changes to the provisions in the contract, valuation rules of 262 variations, Rule 1 of contract's rates and prices, Rule 2 of fair adjustment, Rule 3 of fair market 263 rates and prices, Rule 4 of day-work rates, Rule 5 of omitted work, Rule 6 of re-measurement on 
264 actual quantities (provisional quantity), and additional expense and subsequent circumstances

265 caused by variations. Content refers to the complete list of the generic guidelines/references on

266 the contractual variations, whereas Forum is the platform for the end users to comment or provide

267 feedback on the issue.

268 Subsequently, the database queries and forms were developed from the DWCA tables.

269 The forms are an important feature in the e-DR database. The e-DR interface was developed

270 based on the forms. The final e-DR database file was converted into an executable (exe) file in a

271 template setting. As such, it serves as a read-only analytical database that is used as a foundation

272 for decision making. The portion of the forum for comments or feedbacks is excluded from this,

273 which is deliberately set in an unlocked mode. Overall, the interfaces of the prototype were

274 described in the following sequence, such as:

275 - Front Page: It provides general information that the contents are derived from literature

276 reviews, contract provisions of PAM 2006, legal cases, and the consensus views of experts.

277 A disclaimer is also provided to explain the exclusion of liability.

278 - Main Menu: Subsequently, two options are made available in the main menu interface for 279 retrieving the contents, that is, issues breakdown and keyword searching.

280 - Issues Breakdown: This interface consists of several database forms that were developed 281 from the queries and tables of raw data. It is designed in such a way that users can easily 282 locate the specific sub-issue to be referred to. Users can refer to the guidelines based on the 283 sub-issue after clicking the "Click here for DETAILS" button. The users are able to 284 comment or give their feedback (if any) after referring to the guidelines by clicking "GO to 285 Forum/Comments" button.

286 - Keyword Searching: All the guidelines are allocated in the database. As such, the keyword 287 searching feature would help users to locate the issue or guideline easily. The command 
button "Find and Replace" is used to perform searching. Besides, users are also able to 289 provide their comments in the interface by clicking "GO to Forum/Comments" button.

290 - Forum/Comments: This forum has been deliberately set unlocked with the command 'Auto

291 Number' so that users can comment or discuss in the forum, and all the comments will be 292 automatically stored and appeared here.

293 Data from contract provisions, legal cases, and literatures are organized and uploaded to 294 the warehouse after receiving verification from the local experts. Apart from that, the interface to 295 and from the data warehouse is operated in a batch mode (offline). Operating in an online mode is 296 an appealing option but not very useful in this study (Inmon 2002). This is because the data

297 warehouse needs to get full support or sanction from the local authority and professional bodies 298 in order to publish legal information or contract provisions. This is also to prevent the conflict of 299 interest (Chong et al. 2011). It would lock the database, and the users would not be able to edit 300 the database, except for the feedback or comment section.

302 TESTING AND EVALUATION

304 The e-DR prototype is presented to sixteen professional quantity surveyors who are among the 305 potential end users for testing and evaluation. They are required to rate their satisfaction based on 306 the scores determined by the researchers, that is, $0=$ extremely dissatisfied, $30 \%=$ dissatisfied, $30750 \%=$ neither satisfied nor dissatisfied, $70 \%=$ satisfied, and $100 \%=$ extremely satisfied on five 308 closed-ended questions. The questions were designed around the critical requirements of the 309 DWCA and e-DR. An open question for comment and feedback was also included where the 310 respondents were free to provide their responses. Table 4 shows the results of the prototype 311 evaluation. 
313 prototype. All the variables are above the neutral level (50\%), thus confirming support for the

314 overall score. The usefulness of clarity, practicality, and functionality of the prototype received

315 positive feedback from the respondents. In addition, the respondents had little reservations

316 regarding the coverage of the guidelines on contractual variations. This is evident from the

317 comments posed by the respondents in the open-ended question where they would like to have

318 more discussions and elaborations on the contractual variations issue. In addition, the respondents

319 also suggested a checklist regarding contractual variations. A more detailed checklist and the

320 checklist of contractual variations could be addressed in another area of computing applications

321 or expert systems, which is purposely developed for that particular issue. This is beyond the

322 scope of the research, whereby the DWCA or e-DR is designed to address more generalized

323 contractual problems instead of individual case-based problems.

324 More importantly, many of the respondents felt that the prototype is able to mitigate

325 contractual disputes and enhance their decision-making process compared with the conventional

326 approach, in which the e-DR's contents are well organized and facilitate better understanding

\section{DISCUSSION AND IMPLICATIONS}

330 This research has successfully achieved its objective in terms of bridging the gap between IT 331 application and contract administration, particularly for the construction industry. Specifically, 332 the DWCA and the resulting e-DR prototype have provided evidence of how the data warehouse 333 concept can be incorporated into contract administration to enhance the existing conventional 334 approach whereby the users have to face voluminous and complicated legal documents in a 335 manual way. Both the conceptual models and prototype have been verified and evaluated by

336 reputed experts who further enhanced the functionality and validity of the proposed application.

337 More importantly, the prototype has proved its ability to improve clarity of construction contracts 
338 that greatly influenced the understanding and interpretation of such contracts, especially among 339 users who are without a legal background. Since such a system is non-existent to date, the efforts 340 undertaken represent significant theoretical and practical contributions made in this study.

341 Judging from the evaluation results, it is thereby safe to posit that the e-DR application,

342 when fully developed, could contribute to assisting users in making more informed decisions

343 regarding contractual circumstances in a construction project and subsequently help in

344 overcoming the various contractual issues highlighted in the article, if not all. These are among

345 the two major value propositions of the system. Further, the application may not involve huge

346 investment, as it was developed using Microsoft Access. The use of such a relatively inexpensive

347 but yet user-friendly software is another attractive feature of the application. As such, there is a

348 potential for the application to be shared and employed by various stakeholders such as

349 construction companies, professional bodies, government agencies, and so on so that valuable

350 information can be retrieved, exchanged, and stored in the data warehouse. To start with, the

351 stakeholders first need to be informed of the value propositions of the application so as to garner

352 their support. Besides, the stakeholders and their employees need to be trained on the features of

353 the system. There is also a possibility that a user manual is developed to support the users as they 354 use the application.

355 In addition, generalizing the e-DR application could be carried out, as the conceptual 356 models render a generic approach toward contract administration. However, precaution should be 357 noted when applying the application as certain adjustments are required especially for those 358 countries that practice different legal systems. It is because the application follows Common Law 359 jurisdiction. Nevertheless, the DWCA could serve as a useful reference in terms of its 360 methodology and development, where the application can be modified and referred to suit the 361 varying legal and cultural circumstances.

362 Notwithstanding the proactive approach proposed for the construction contract 363 administration, two major limitations need to be considered. First, the keyword searching using 
364 the Boolean method requires exact keywords or terms in order to effectively retrieve information.

365 Further, the method does not do performance ranking for the retrieved information (Mitra and

366 Chaudhuri 2000). As such, future development, particularly the use of plain English, is

367 imperative so that the users can locate keywords or terms that they are familiar with instead of

368 having to use legal jargons.

369 Second, although the validity of the conceptual models and e-DR application have been

370 tested and proved to be valid, it is worth noting that the e-DR prototype evaluated in this study

371 was confined to the disputes on contractual variations. There are many other issues plaguing the

372 industry that were not captured in the application as well as other contractual forms. It is only by

373 having a full suite of e-DR application that an effective evaluation of the features, contents, and

374 characteristics of the system can be carried out. This includes the various characteristics of user

375 acceptance on the IT application itself. Future research is warranted to address these limitations.

377 CONCLUDING REMARKS

379 This study provides a working example of how the DWCA conceptual models worked through 380 the development and evaluation of the e-DR prototype. More importantly, the application is 381 proven to help users make more informed decisions regarding contractual circumstances in 382 construction projects. The findings show that the conceptual DWCA model explains a more 383 clarified and accurate means of construction contract administration. The e-DR prototype, on the 384 other hand, is proven to be user-friendly, reliable, and organized information to assist users or 385 construction practitioners in Malaysia, particularly those without legal backgrounds, to analyze 386 circumstances and make informed decisions compared to the conventional contract administration 387 approach by which users are bogged down by the voluminous and complicated contract 388 documents and provisions. It is hoped that future works are undertaken to develop a full suite of 389 e-DR application. Since judgments from litigation cases create numerous legal views or positions 
390 into the practice of contract administration, a research on the clauses to be taken into account by 391 contract drafters and experts is warranted. The resulting findings can be used as a basis to expand

392 the research to other countries with similar or different legal systems so that a unified application

393 can be developed. From the knowledge management (KM) perspective, the development of a KM

394 system that captures the input from different users is also possible in order to overcome the

395 contractual disputes and to learn from each other of how construction contracts can be better

396 administered. This will help avoid misunderstanding and interpretation of construction contracts

397 and ultimately lead to harmonious working relationships between the contracting parties.

399 Acknowledgment

400 This research is supported and funded by Construction Research Institute of Malaysia (CREAM) 401 for Vote Number 4405/C01, under the Construction Industry and Development Board, Malaysia.

\section{References}

404 Ajam, M., Alshawi, M., and Mezher, T. (2010). "Augmented process model for e-tendering: Towards 405 integrating object models with document management systems.” Auto. in Constr., 19(6), 762-778.

406 Anastasopoulos, P. C., Labi, S., Bhargava, A., Bordat, C., and Mannering, F. L. (2010). "Frequency of 407 change orders in highway construction using alternate count-data modeling methods.” J. Constr. Eng. $408 \quad$ Manage., 136(8), 886-893.

409 Broome, J. C., and Hayes, R. W. (1997). "A comparison of the clarity of traditional construction contracts 410 and of the New Engineering Contract.” Int. J. Project Manage., 15, 255-261.

411 Charles, J., and Bruce, F.D. (1990). "Investigation into construction disputes." J. Manage. in Eng., 6(1), $412 \quad 39-46$.

413 Chau, K. W. (2007). "Application of a PSO-based neural network in analysis of $414 \quad$ outcomes of construction claims.” Auto. in Constr., 16(5), 642-646.

415 Chau, K. W., Cao, Y., Anson, M., and Zhang, J. (2002). "Application of data warehouse and Decision 416 Support System in construction management.” Auto. in Constr., 12(2), 213- 224. 
417 Chen, J-H. (2008). "KNN based knowledge-sharing model for severe change order disputes in 418 construction.” Auto. in Constr., 17(1), 773-779.

419 Chen, D-N., Liang, T-P., Lin, B. (2010). "An Ecological Model for Organizational Knowledge 420 Management.” J. Comp. Info. Syst., 50(3), 11-22.

421 Chen, P.-H., Wan, C., Tiong, R. L. K., Ting, S. K., and Yang, Q. (2004). "Augmented IDEF1-based 422 process oriented information modeling.” Auto. in Constr., 13(6), 735-750.

423 Cheng, M. Y., Tsai, H. C., and Chiu, Y. H. (2009). "Fuzzy case-based reasoning for coping with $424 \quad$ construction disputes.” Exp. Syst. with App., 36(2), 4106-4113.

425 Cheung, S. O., Kenneth, T. W. Y., and Henry, S. (2004). “Construction negotiation online.” J. Constr. Eng. 426 Manage., 130(6), 844-852.

427 Cheung, S. O., and Yiu, T. W. (2007). "A study of construction mediator tactics - part I: taxonomies of 428 dispute sources, mediator tactics and mediation outcomes.” Build. \& Envir., 42(2), 752-761.

429 Chong, H.Y., Balamuralithara, B., and Chong S.C. (2011). "Construction Contract Administration in 430 Malaysia Using DFD: A Conceptual Model," Indus. Manage. \& Data Syst., 111(9), 1449-1461.

431 Chong, H. Y., and Zin, R. M. (2010). "A case study into the language structure of construction standard 432 form in Malaysia.” Int. J. Pro. Manage., 28(6), 601-608.

433 Gupta, H., and Mumick, I. S. (2005). "Selection of views to materialize in a Data Warehouse." IEEE Trans. $434 \quad$ on Know.and Data Eng., 17(1), 24-43.

435 Hwang, M. I., and Xu, H. (2008). “A structural model of data warehousing success.” J. Comp. Info. Syst., 436 49(1), 48-56.

437 Inmon, W. H. (2002). Building the Data Warehouse, third edition. John Wiley \& Sons, Inc, New York.

438 Inmon, W. H. and Hackathorn, R. D. (1994). Using the Data Warehouse - Instruction and Assessment. $439 \quad$ John Wiley \& Sons, New York.

440 Inmon, B., and Valente, G. (2010). A Peek into the Future: The Next Wave of Data Warehousing. 441 Retrieved March 3, 2010, from http://tdwi.org/Articles/2010/02/03/Next-Wave-DW.aspx?Page=1.

442 Kassab, M., Hipel, K., and Hegazy, T. (2006). "Conflict resolution in construction disputes using the Graph 443 Model.” J. Constr. Eng. Manage., 132(10), 1043-1052. 
444 Kim, H., Soibelman, L., and Grobler, F. (2008). "Factor selection for delay analysis using Knowledge 445 Discovery in Databases.” Auto. in Constr., 17(5), 550-560.

446 Kraiem, Z. M. (1988). DISCON: An Expert System for Construction. University of Colorado, Doctoral $447 \quad$ Thesis.

448 Kuo, Y. F., and Chen, P. C. (2008). "Constructing performance appraisal indicators of mobility of the 449 service industries using Fuzzy Delphi Method. ” Exp. Syst. with App., 35(4), 1930-1939.

450 Liang, S-K.., Hsieh, S-Y., and Ling, H-C. (2006). "Determinants of the assignment of managers to foreign 451 ranches by banks, using the Fuzzy Delphi method.” Int. J. of Manage., 3(2), 261-271.

452 Luo, W. H., and Tung, Y. (1999). “A framework of selecting process modelling methods.” Indust. Manage. 453 \& Data Syst., 99(7), 312-319.

454 Mitra, M., and Chaudhuri, B. B. (2000). "Information Retrieval from Documents: A Survey." Info. $455 \quad$ Retrieval, 2, 141-163.

456 Moselhi, O., Assem, I., and El-Rayes, K. (2005). "Change orders impact on labor productivity.” J. Constr. $457 \quad$ Eng. Manage., 131(3), 354-359.

458 Nitithamyong, P., and Skibniewski, M. J. (2004). "Web-based construction project management systems: 459 how to make them successful." Auto. in Constr., 13(2), 491- 506.

460 Perkins, R. A. (2009). "Sources of changes in design - Build contracts for a governmental owner." J. $461 \quad$ Constr. Eng. Manage., 135(7), 588-593.

462 Rahman, N. (2007). "Refreshing data warehouses with near real-time updates." J. Comp. Info. Syst., 47(3), $463 \quad 71-80$.

464 Rameezdeen, R., and Rajapakse, C. (2007). "Contract interpretation: The impact of readability." Constr. $465 \quad$ Manage.t and Eco., 25 (7), 729-737.

466 Robinson, N., Betts, M., and Santhanam, J. (1991). "Expert systems for construction contract 467 interpretation," Proceedings of Mini-Conference on Expert System Applications in Construction 468 Contract Law. June 24-26. Bangkok, AIT, 50-67.

469 Romero, O., and Abelló, A. (2010). “A framework for multidimensional design of data warehouses from 470 ontologies.” Data Know. \& Eng., 69(11), 917-942. 
471

472

473 Russell, A. D., Chiu, C-Y., and Korde, T. (2009). "Visual representation of construction management

Rujirayanyong, T. and Shi, J. J. (2006). “A project-oriented data warehouse for construction.” Auto. in Constr., 15(6), 800-807. data." Auto. in Constr., 18(8), 1045-1062.

Semple, C., Hartman, F.T., Jergeas, G. (1994). "Construction claims and disputes: Causes and cost/time overruns.” J. Constr. Eng. Manage., 120(4), 785-795.

Serag, E., Oloufa, A., Malone, L., and Radwan, E. (2010). "Model for quantifying the impact of change orders on project cost for U.S. roadwork construction.” J. Constr. Eng. Manage., 136(9), 1015-1027.

Shumway, R., Richard, A., and Ritti, J. (2004). "New trends and bad results in construction contracts." Leadership and Manage. in Eng., 4(3), 93-104.

Sim, K. C., and Molnenaar, K. (2000). "Prediction of construction disputes in change issues," Proceedings of Construction Congress VI: Building Together for a Better Tomorrow in an Increasingly Complex World, 20-22 February, Orlando, 534-542.

Srivastava, J., and Chen, P-Y. (1999). “Warehouse Creation: A Potential Roadblock to Data Warehousing.” IEEE Trans. on Know. \& Data Eng., 11(1), 118-126.

Theodoratos, D., and Sellis, T. (1999). “Design data warehouse,” Data \& Know. Eng., 31(3), 279- 301.

Thomas, H. R., Smith, G. R., and Mellott, R. E. (1994). “Interpretation of construction contracts.” J. Constr. Eng. Manage., 120(2), 321-336.

Zaneldin, E. K. (2006). "Construction claims in United Arab Emirates: Types, causes, and frequency.” Int. J. Project Manage., 24, 453-459. 


\section{- Authorized Person and Power}

> The right Person is the Professional Architect or other form of practice registered under Architect Act 1967 and named in the contract.

$>$ Architect issues variations or sanctions contractor's variations provided that the variation will not vitiate the original contract.

$>$ Architect's power is restricted, which he can't omit a work and give it to another contractor.

$>$ If Architect issues variations that outside the scope of Contract and without expressed authority from the Employer, he may be liable to the Employer.

\section{- Period of Issuance}

$>$ Architect can issue variations at any time before issuance of the Certificate of Practical Completion (CPC).

- But, after CPC period, the variations must be necessitated by obligations or compliance with the local authorities and service providers' requirements towards the Work, or

$>$ Contractor shall conform to the local authorities and service providers' requirements and proceed with the work if no $\mathrm{AI}$ in response for the inconsistencies with statutory requirements within 7 days of the given written notice.

$>$ AI to rectify Contractor's default is not considered as a variation either before or after the CPC.

\section{- Provisional Sums}

$>$ There are two parts of 'provisional' items for variations, that is, Provisional Quantity and expenditure of Provisional Sums.

> Provisional Quantity means the estimated quantities of work, materials or goods in the BQ which cannot be determined or detailed at the time.

- Provisional Quantity describes as the tasks are with rates and prices for the pre-estimate quantity and it subject to re-measurement for the actual value.

$>$ Provisional Sums means Sums provided in the Contract and/or for Nominated Sub-Contract for work, materials or goods in the BQ which cannot be determined or detailed at the time.

- Expenditure of Provisional Sums describes as the tasks but without detailed information for its quantity, and rates.

> Provisional Quantity does not necessary require an AI for carrying out the work, like piling length in the Bill of Quantities (BQ).

$>$ AI is mandatory for expenditure of Prime Cost Sums or Provisional Sums.

PART B: VALIDITY OF VARIATIONS

- Written Instruction

- Definition/Principle of Variation

- Addition

- Omission

- Substitution

- Alteration of the Kind or Standard of Materials or Goods

- Removal of the Executed Works, Materials and Goods

- Changes to the provisions in the Contract

\section{PART C: VALUATION RULES OF VARIATIONS}

- Valuation Rules of Variations

- Rule 1 of Contract Rates and Prices

- Rule 2 of Fair Adjustment

- Rule 3 of Fair Market Rates and Prices

- Rule 4 of Daywork Rates

- Rule 5 of Omitted work

- Rule 6 of Re-measurement on Actual Quantities (Provisional Quantity)

PART D: OTHERS

- Additional Expenses and Subsequent Circumstances Caused by Variations 
Table 1. Characteristics of previous studies in contract administration

\begin{tabular}{|c|c|c|c|c|c|c|c|}
\hline System/Name & Year & $\begin{array}{c}\text { Method of } \\
\text { decision } \\
\text { making } \\
\text { /process } \\
\end{array}$ & $\begin{array}{c}\text { Historical } \\
\text { data/ court } \\
\text { case }\end{array}$ & $\begin{array}{l}\text { Panel } \\
\text { of } \\
\text { expert }\end{array}$ & $\begin{array}{c}\text { Reference } \\
\text { of Standard } \\
\text { Form }\end{array}$ & $\begin{array}{l}\text { Targeted } \\
\text { Issue }\end{array}$ & $\begin{array}{c}\text { Use } \\
\text { of } \\
\text { IT } \\
\text { tool }\end{array}$ \\
\hline $\begin{array}{l}\text { DISCON } \\
\text { (Kraiem 1988) }\end{array}$ & 1988 & Flow chart & Yes & Yes & Yes & $\begin{array}{l}\text { Differing } \\
\text { site } \\
\text { condition }\end{array}$ & No \\
\hline $\begin{array}{l}\text { Expert System } \\
\text { For } \\
\text { Construction } \\
\text { Contract } \\
\text { Interpretation } \\
\text { (Robinson et al. } \\
\text { 1991) }\end{array}$ & 1991 & Rule based & Yes & Yes & Yes & $\begin{array}{l}\text { Contract } \\
\text { Interpretatio } \\
\mathrm{n}\end{array}$ & No \\
\hline $\begin{array}{l}\text { Prediction of } \\
\text { Construction } \\
\text { Disputes (Sim } \\
\text { and Molnenaar } \\
\text { 2000) }\end{array}$ & 2000 & $\begin{array}{l}\text { Case-based } \\
\text { reasoning }\end{array}$ & Yes & No & No & $\begin{array}{l}\text { Most severe } \\
\text { contractual } \\
\text { issues }\end{array}$ & No \\
\hline $\begin{array}{l}\text { Claim database } \\
\text { management } \\
\text { (Al-Sabah et al. } \\
\text { 2003) }\end{array}$ & 2003 & $\begin{array}{l}\text { Relational } \\
\text { database }\end{array}$ & Yes & No & Yes & $\begin{array}{l}\text { General } \\
\text { disputes and } \\
\text { claims }\end{array}$ & Yes \\
\hline $\begin{array}{l}\text { CoNegO } \\
\text { (Cheung et al. } \\
\text { 2004) }\end{array}$ & 2004 & Even Swaps & No & No & No & $\begin{array}{l}\text { Figure based } \\
\text { disputes }\end{array}$ & Yes \\
\hline $\begin{array}{l}\text { PSO-based on } \\
\text { Construction }\end{array}$ & 2004 & $\begin{array}{l}\text { PSO-based } \\
\text { neural }\end{array}$ & Yes & No & No & $\begin{array}{l}\text { Construction } \\
\text { claims }\end{array}$ & Yes \\
\hline $\begin{array}{l}\text { Claims } \quad \text { (Chau } \\
\text { 2007) }\end{array}$ & & network & & & & & \\
\hline $\begin{array}{l}\text { Graph Model } \\
\text { (Kassab et al. } \\
\text { 2006) }\end{array}$ & 2006 & $\begin{array}{l}\text { Prisoner's } \\
\text { dilemma } \\
\text { strategy }\end{array}$ & No & No & No & $\begin{array}{l}\text { General } \\
\text { Dispute's } \\
\text { Problem }\end{array}$ & No \\
\hline $\begin{array}{l}\text { FCBR (Cheng } \\
\text { et al. 2009) }\end{array}$ & 2009 & $\begin{array}{l}\text { Fuzzy case- } \\
\text { based } \\
\text { reasoning }\end{array}$ & Yes & No & No & $\begin{array}{l}\text { General } \\
\text { construction } \\
\text { disputes }\end{array}$ & Yes \\
\hline $\begin{array}{l}\text { Model of data } \\
\text { warehousing for } \\
\text { contract } \\
\text { administration } \\
\text { (Chong et al. } \\
\text { 2011) }\end{array}$ & & $\begin{array}{l}\text { Data Flow } \\
\text { Diagram } \\
\text { (DFD) }\end{array}$ & Yes & Yes & No & $\begin{array}{l}\text { General } \\
\text { contractual } \\
\text { disputes }\end{array}$ & No \\
\hline
\end{tabular}


Table 2. Background of the experts

\begin{tabular}{|c|c|c|c|c|c|c|}
\hline \multirow[t]{2}{*}{ Group } & \multicolumn{6}{|c|}{ Expertise } \\
\hline & $\begin{array}{l}\text { Registered } \\
\text { arbitrator or } \\
\text { legal } \\
\text { professional }\end{array}$ & $\begin{array}{l}\text { Registered } \\
\text { and } \\
\text { professional } \\
\text { architect } \\
\end{array}$ & $\begin{array}{l}\text { Registered } \\
\text { and } \\
\text { professional } \\
\text { engineer } \\
\end{array}$ & $\begin{array}{c}\text { Registered } \\
\text { and } \\
\text { professional } \\
\text { QS } \\
\end{array}$ & $\begin{array}{c}\text { Project } \\
\text { management } \\
\text { and contract } \\
\text { administration }\end{array}$ & $\begin{array}{c}\text { Construction } \\
\text { contract } \\
\text { drafting }\end{array}$ \\
\hline \multicolumn{7}{|l|}{ Legal } \\
\hline L1 & $\sqrt{ }$ & & & $\sqrt{ }$ & $\sqrt{ }$ & $\sqrt{ }$ \\
\hline L2 & $\sqrt{ }$ & $\sqrt{ }$ & & & $\sqrt{ }$ & $\sqrt{ }$ \\
\hline L3 & $\sqrt{ }$ & & & & & $\sqrt{ }$ \\
\hline \multicolumn{7}{|l|}{ Architect } \\
\hline A1 & & $\sqrt{ }$ & & & $\sqrt{ }$ & $\sqrt{ }$ \\
\hline A2 & & $\sqrt{ }$ & & & $\sqrt{ }$ & \\
\hline A3 & & $\sqrt{ }$ & & & $\sqrt{ }$ & \\
\hline \multicolumn{7}{|l|}{ Engineer } \\
\hline E1 & $\sqrt{ }$ & & $\sqrt{ }$ & & $\sqrt{ }$ & $\sqrt{ }$ \\
\hline E2 & $\sqrt{ }$ & & $\sqrt{ }$ & & $\sqrt{ }$ & \\
\hline E3 & $\sqrt{ }$ & & $\sqrt{ }$ & & $\sqrt{ }$ & \\
\hline \multicolumn{7}{|l|}{ Quantity } \\
\hline Surveyor & & & & & & \\
\hline Q1 & $\sqrt{ }$ & & & $\sqrt{ }$ & $\sqrt{ }$ & $\sqrt{ }$ \\
\hline Q2 & & & & $\sqrt{ }$ & $\sqrt{ }$ & $\sqrt{ }$ \\
\hline Q3 & & & & $\sqrt{ }$ & $\sqrt{ }$ & \\
\hline
\end{tabular}


Table 3. Contractual issues in the three work stages

\begin{tabular}{|c|c|c|}
\hline $\begin{array}{c}\text { Pre-contract award } \\
\text { stage }\end{array}$ & Construction or commencement of work stage & Work completion stage \\
\hline \begin{tabular}{ll}
\multicolumn{2}{l}{ SEVEN areas: } \\
1. & Estimating and \\
& pricing \\
2. & Design \\
& information \\
3. & Insurances \\
4. & Performance bond \\
& submission \\
5. & Site possession \\
6. & Tender \\
& documentation \\
& and requirements \\
7. & Work program
\end{tabular} & $\begin{array}{ll}\text { TWENTY THREE areas: } \\
\text { 1. } \\
\text { 2. } & \text { Compensation/loss and expenses } \\
\text { 3. } & \text { Default on notice } \\
\text { 4. } & \text { Delay and extension of time } \\
\text { 5. } & \text { Discrepancy and inconsistency of } \\
\text { information } \\
\text { 6. } \\
\text { 7. } \\
\text { Interference/problem by subcontractors and } \\
\text { 8. } \\
\text { 9. Interference/problem by professionals } \\
\text { 10. } \\
\text { 11. Partial possession } \\
\text { 12. Postod of honoring certificates } \\
\text { 13. Practical completion } \\
\text { 14. Quality of workmanship } \\
\text { 15. Set off by employer } \\
\text { 16. Site and nature of work } \\
\text { 17. Standard and quality of material } \\
\text { 18. Statutory obligations } \\
\text { 19. Supply difficulties } \\
\text { 20. } \\
\text { 21. } & \text { Valuation and inspection } \\
\text { 22. } & \text { Contractual variations } \\
\text { 23. } & \text { Weather }\end{array}$ & 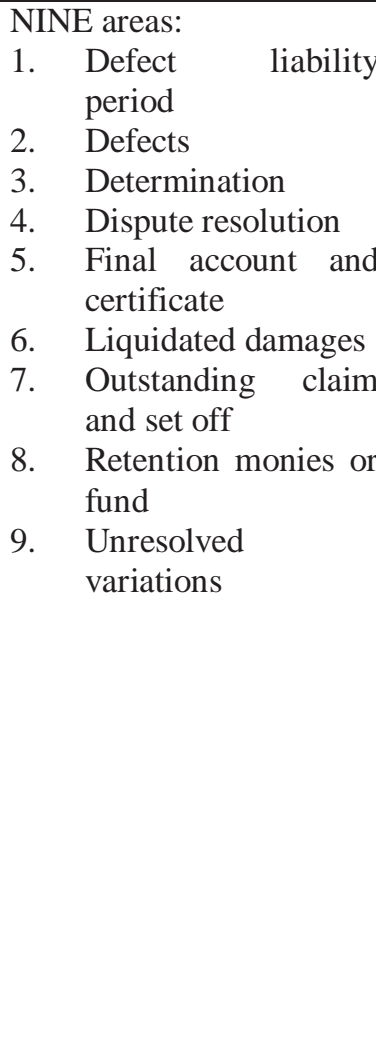 \\
\hline
\end{tabular}


Table 4. Analysis of prototype evaluation

\begin{tabular}{clccc}
\hline No & \multicolumn{1}{c}{ Testing variables } & Mean (\%) & Interpretation \\
\hline 1 & $\begin{array}{l}\text { The usefulness of clarity aspects in contract } \\
\text { administration for the references }\end{array}$ & 75.6 & Satisfying \\
2 & $\begin{array}{l}\text { The practicality of the e-DR to provide references and } \\
\text { alertness to the users }\end{array}$ & 74.4 & Satisfying \\
3 & $\begin{array}{l}\text { The functionality of e-DR's structure in terms of its } \\
\text { features and interfaces }\end{array}$ & 70 & Satisfying \\
4 & $\begin{array}{l}\text { The coverage of the generic references concerning } \\
\text { contractual variations }\end{array}$ & 66.9 & Slightly satisfying \\
5 & Overall & 74.1 & Satisfying \\
\hline
\end{tabular}




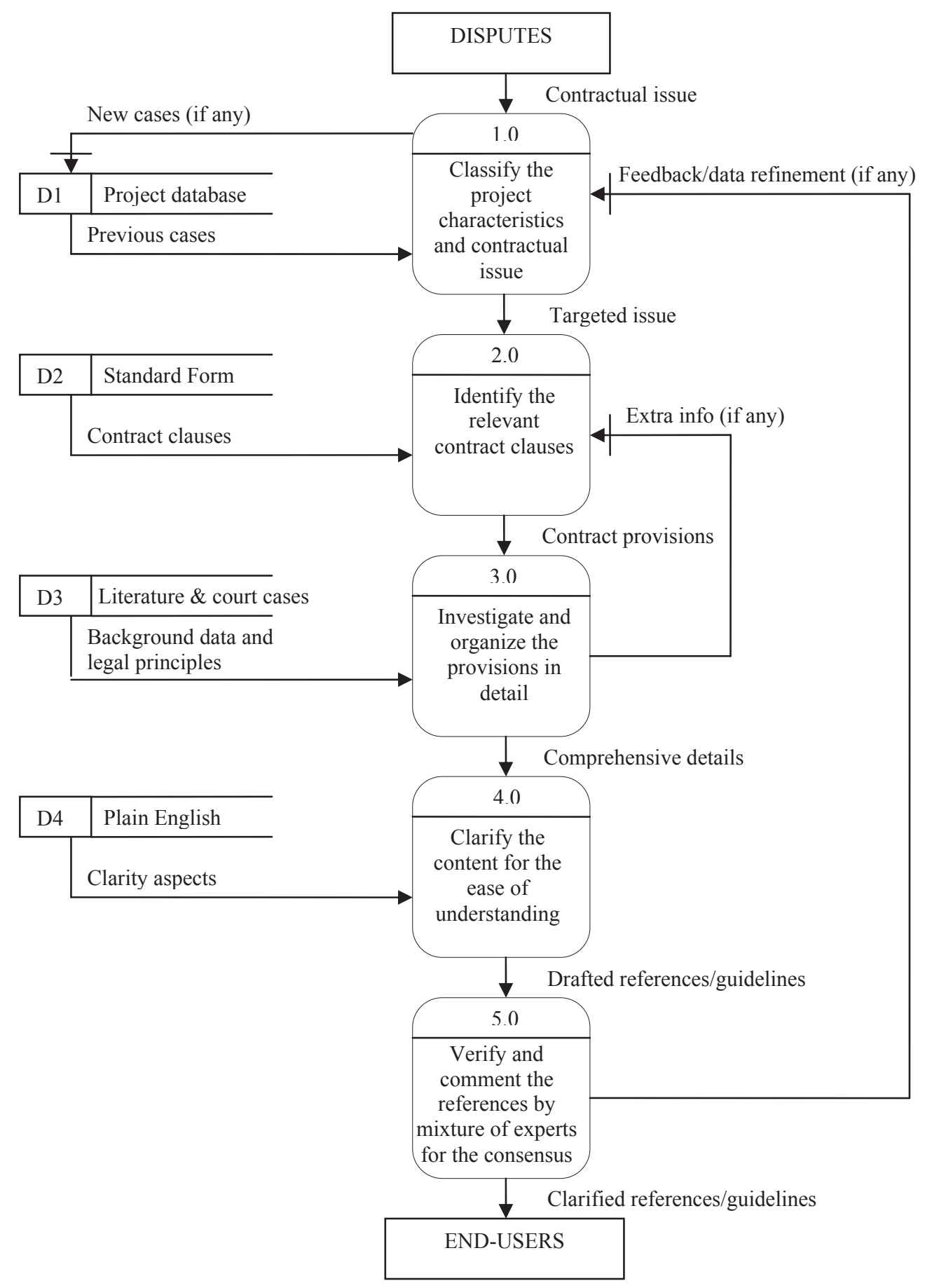

Fig. 1. Level-0 DFD of e-DR's contents 


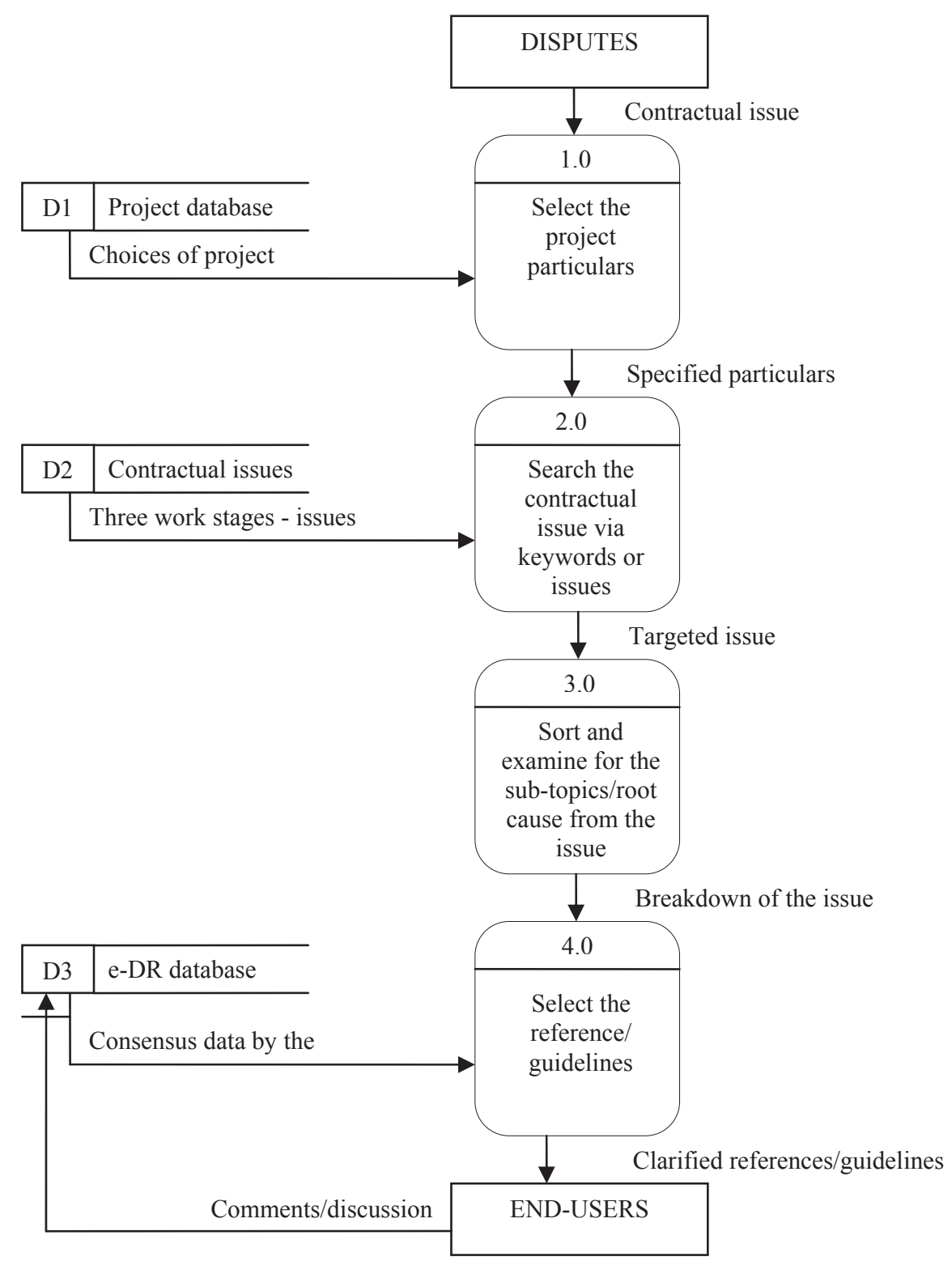

Fig. 2. Level-1 DFD of e-DR's features 
Click here to download Figure: ASCE1-Fig. 3.pdf

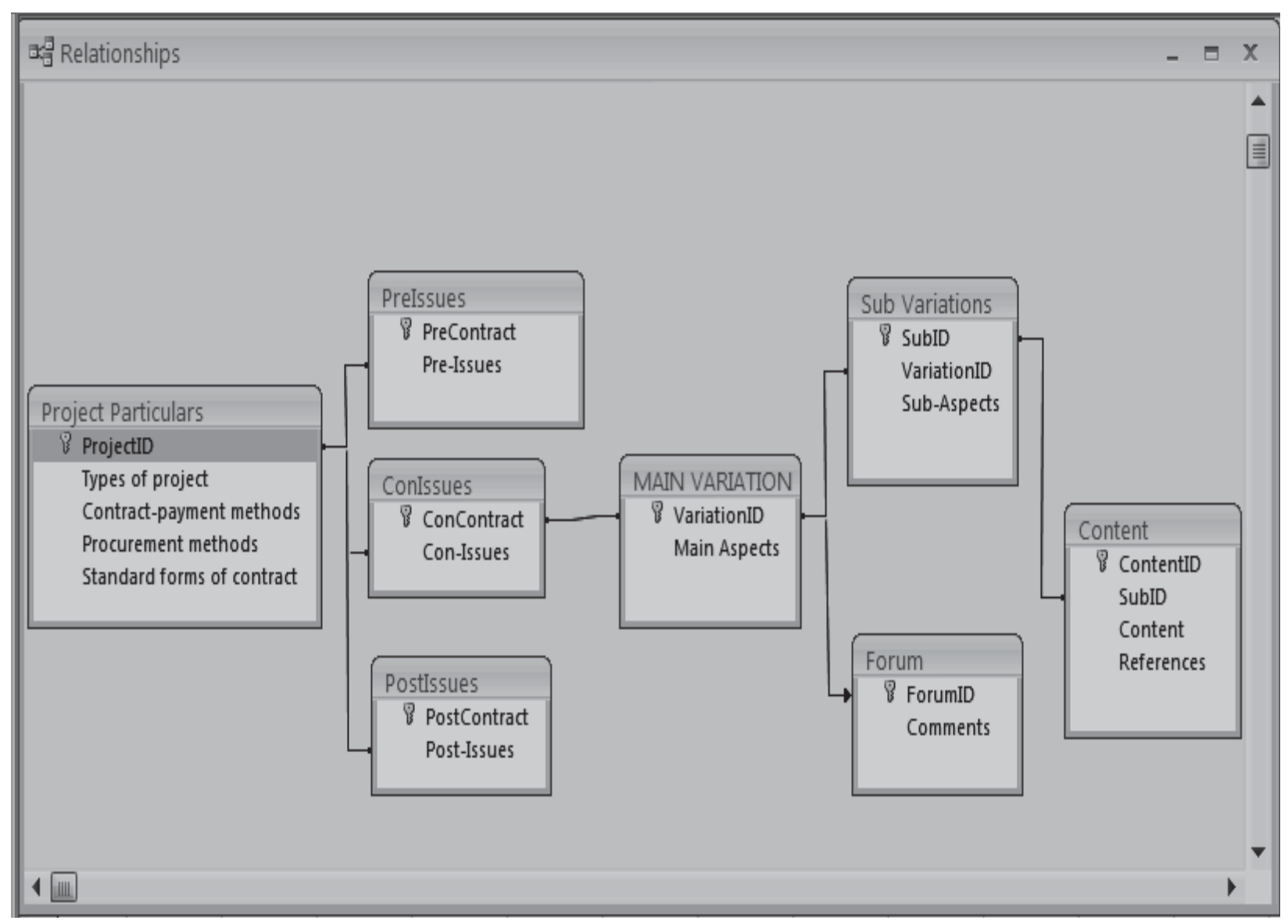

Fig. 3. Relationship between tables in e-DR database 